\title{
O SIG COMO FERRAMENTA DE ANÁLISE DA PAISAGEM: O CASO DO MANGUE NO BAIRRO DE SÃO DOMIGOS EM ILHÉUS-BA
}

\author{
THE GIS AS A TOOL OF LANDSCAPE ANALYSIS: THE CASE OF THE MANGROVE IN SÃO \\ DOMINGOS NEIGHBORHOOD IN ILHÉUS - BA
}

\section{OLIVEIRA, Olga Maria Góes de}

Arquiteta, estudante do Programa de Mestrado em Engenharia Ambiental Urbana - UFBA.

E-mail: olgaoliveirameau@yahoo.com.

\section{CUNHA, Rita Dione Araújo}

Doutora e professora Adjunta da Faculdade de Arquitetura da UFBA. E-mail: ritadi@uol.com.br.

\section{RESUMO}

Dentre as paisagens naturais em regiões litorâneas, os mangues representam um tipo de ecossistema freqüentemente invadido pelas ações antrópicas dentro de áreas urbanas. As técnicas de SIG (Sistemas de Informações Geográficas) surgem como elementos importantes na detecção de problemas e análise da ocupação do solo urbano bem como das transformações da paisagem. Este artigo apresenta um exemplo de utilização de SIG em relação à ocupação de áreas verdes de mangue em Ilhéus - BA, visando estudar um bairro específico da cidade, onde a transformação da paisagem sofreu um forte impacto nas últimas décadas.

Palavras-chave: SIG, paisagem, mangue, uso e ocupação do solo.

\begin{abstract}
Among the natural landscapes in coastal regions, the mangrove represents a type of ecosystem frequently invaded by human actions inside urban areas. GIS (Geographic Information Systems) techniques appear as important elements for detecting the problems and analysis of urban soil occupation changes in landscapes. This paper presents an example of the use of GIS regarding the occupation of green areas of mangrove in Ilhéus - BA, in order to study a specific neighborhood of the town, where landscape changes have suffered a strong impact in the last decades.
\end{abstract}

Key words: GIS, landscape, mangrove, use and soil occupation.

\section{1) Introdução}

A paisagem urbana é o resultado de grandes transformações antrópicas sobre o meio físico ao longo dos anos. O processo histórico de ocupação do espaço urbano, bem como suas transformações, em uma determinada época ou sociedade faz com que o meio ambiente tenha um caráter dinâmico e a paisagem adquira características mutantes. O conhecimento da formação e da evolução histórica do espaço urbano, sua implantação, seu parcelamento e sua ocupação oferece ao pesquisador do espaço urbano uma visão ampla da realidade, pois permitirá através dos anos, compreender como esse espaço atingiu o estado atual e quais as mudanças que a sociedade vem promovendo sobre o mesmo e sobre o meio natural.

A expansão urbana desordenada sobre ambientes costeiros tem determinado intensas degradações ambientais, trazendo sérias conseqüências para as comunidades humanas. Dentre os ambientes naturais que mais sofrem as conseqüências da ocupação do solo nas cidades brasileiras litorâneas, atualmente, estão os ecossistemas hídricos como as áreas de mangues. No Brasil, este ecossistema faz parte da Mata Atlântica, um dos biomas mais ricos em diversidades das Américas, perfazendo cerca de $25.000 \mathrm{~km}^{2}$ de paisagem de manguezais (Ramos, 2002, p.86). Podem ser citados como principais fatores responsáveis pela alteração e/ou destruição 
dos mangues: os assentamentos humanos, a expansão urbana, o lançamento de esgotos, a disposição de resíduos sólidos, os lançamentos de efluentes industriais, a produção de sal, a pesca e a extração mineral com a produção de petróleo, gás natural e carvão.

O geoprocessamento (processamento informatizado de dados georreferenciados) e as técnicas de SIG (Sistema de Informação Geográficas) aparecem como ferramentas muito importantes na análise da evolução urbana e da degradação da paisagem natural decorrente das intervenções antrópicas. Através de informações derivadas de análises de dados geoprocessados, pode-se ter idéia de como o processo de expansão urbana e mais precisamente como a ocupação do solo interfere na transformação das paisagens naturais.

Pretende-se neste trabalho apresentar uma análise da transformação da paisagem natural de mangue situado numa área urbana de llhéus no estado da Bahia. Ressalta-se que o trabalho é parte de uma pesquisa de mestrado desenvolvido no Programa de Mestrado em Engenharia Ambiental Urbana da Universidade Federal da Bahia que visa diagnosticar e analisar a ocupação do solo da cidade de llhéus/ Ba e em especial nas suas áreas de manguezais. Espera-se através dessa análise contribuir para a compreensão da forma como se deu à expansão urbana nessas áreas, bem como suas conseqüências para a população e para o meio ambiente.

Para este artigo, apresenta-se a metodologia adotada para coletar os dados sobre as transformações da paisagem do mangue no Bairro de São Domingos em llhéus que é a área de estudo recortada para a pesquisa. A ferramenta "SIG" é utilizada aqui para obtenção de dados sobre a paisagem do mangue estudada para prover informações sobre os processos ocupacionais e de expansão urbana para subsidiar estudos de preservação dos recursos naturais e paisagísticos importantes como as áreas de mangue. Não são apresentadas conclusões neste trabalho, porque as análises ainda estão sendo desenvolvidas na pesquisa, cabendo aqui apenas ressaltar a importância da ferramenta SIG nos processos de estudo da paisagem.

\section{2) Aspectos conceituais sobre mangues e sua importância como paisagem natural}

manguezal é um ecossistema costeiro de transição entre os ambientes terrestre e marinho associado às margens de baías, enseadas, barras, desembocaduras de rios, lagunas e reentrâncias costeiras, onde haja encontro de águas de rios com a do mar, ou diretamente com a linha da costa. Segundo Maciel (1991, p.9), o manguezal "é um sistema ecológico costeiro tropical, dominado por espécies típicas, às quais se associam a outros componentes da flora e da fauna, microscópicos e macroscópicos, adaptados a um substrato periodicamente inundado pelas marés, com grandes variações de salinidade".

O fato dos manguezais constituírem uma barreira de proteção das áreas ribeirinhas e serem o elo de ligação entre o mar e a terra firme, faz com que recebam riquíssimos compostos orgânicos como restos de folhas, galhos e frutos das árvores, excrementos de animais e sais minerais da própria terra, produzindo alimentos energético rico em proteínas para diversos componentes da fauna estuarina e marinha, formando a base para diversas cadeias alimentares. Além da produção da matéria orgânica, a estrutura das raízes de mangue, formando emaranhados, oferece proteção para espécies da fauna marinha, durante os primeiros estágios de vida, contra seus predadores, formando um refúgio para diversas espécies animais ameaçadas de extinção, principalmente aves marinhas que neles encontram uma das poucas áreas costeiras em que a atividade humana é reduzida (Ramos, 2002, p.99).

manguezal possui ainda grande importância social, pois apresenta fonte de renda para população ribeirinha. Algumas comunidades de extratores de recursos do mangue se desenvolvem na proximidade deste ambiente, construindo cooperativas organizadas. Além da fauna e da 
flora que são utilizados, os manguezais protegem a linha da costa e as margens dos estuários contra erosão e enchentes, diminuindo a força das águas; filtram os polventes, reduzindo a contaminação das praias, podendo transforma-se em local para atividades educacionais, turísticas e de recreação. A degradação de uma área de mangue, portanto, causa um grande impacto negativo ao ambiente, sendo preciso controlar as ações antrópicas em prol da manutenção não só do mangue, mas das áreas adjacentes.

Até as primeiras décadas do século XX, as áreas de mangue no Brasil eram exploradas de forma pouca intensa para a pesca, construção de "viveiros" de peixes (aqüicultura) e retirada de material para construção de casa e cercos, sendo que, no Rio Grande do Norte, começavam a serem utilizadas para construção de salinas (LACERDA, 1991, p.195). Pelo mesmo autor, a partir da década de 50, as paisagens de áreas estuarinas e de mangue passam a ser transformadas para dar lugar à implantação de indústrias e expansão imobiliária, causando além da degradação dos ecossistemas, um empobrecimento ainda maior das populações tradicionais que dependem dele para sobreviver.

Como elementos paisagísticos, os mangues favorecem a área urbana com a presença do verde e não deveria ser desprezado em projetos de expansão urbana. Ao contrário, deveria ser valorizado com a criação de parques de caráter de preservação da área natural, através de legislações urbanísticas que orientassem a ocupação do solo, garantindo faixas extensas de mangue para preservação da paisagem típica. Tentativas dessa natureza foram feitas em várias regiões do Brasil, a exemplo da cidade de Florianópolis, em Santa Catarina, onde foram feitas intervenções em áreas de mangue com passarelas para visitação ao ecossistema. Parques dessa natureza auxiliam também um incremento na educação ambiental, aproximando a população para apreciar e aprender a enxergar o mangue como uma paisagem natural importante para a manutenção de vidas.

\section{3) A área de estudo}

A Cidade de llhéus no litoral da Bahia é recortada por diversos rios, cujo sítio urbano desenvolveu-se próximo a áreas alagadas, local de existência de complexos ecossistemas, como os manguezais. A cidade localiza-se, aproximadamente, entre os meridianos de $39^{\circ} 00^{\prime}$ e $39^{\circ} 04^{\prime}$ W, e os paralelos $14^{\circ} 44^{\prime}$ e $14^{\circ} 51^{\prime}$ S, na zona fisiográfica denominada Região Cacaveira da Bahia e Região Econômica Litoral Sul do Estado da Bahia (SEPLANTEC / CEl, 1996). Situada sobre o estuário formado pelos rios Cachoeira, Almada, Santana e Fundão, caracteriza-se por uma excepcional paisagem, com a presença de extenso litoral, de morros, de matas, de mangues, de rios, de restingas e de recifes.

Atualmente a cidade vem experimentando acentuada expansão urbana resultante da emigração da população rural frente à crise da lavoura cacaueira e do desenvolvimento turístico e industrial. A falta de uma política habitacional para a população de baixa renda foi responsável pelo aumento das ocupações irregulares em todo o país, o que não fez de llhéus uma exceção. A ocupação desordenada, muitas vezes ocorrida por meio de invasão de terrenos desvalorizados ou voltados para a preservação, tornou-se prática comum no país, devido à falta de infra-estrutura urbana. Encostas íngremes, várzeas inundáveis, beiras de rios e cursos d囚água, manguezais, terrenos destinados a serviços públicos, tais como futuras praças e ruas foram ocupados.

Com a crise da cultura do cacau na região sul do Estado da Bahia (incluindo a cidade de llhéus), desde meados do século XX, causada, entre outros, pela queda sucessiva da produção devido a irregularidades climáticas, níveis elevados de estoque condicionando longa permanência de preços baixos e a doença vassoura-de-bruxa (Crinipellis perniciosa), cerca de 200.000 empregos foram perdidos, contribuindo para uma migração para as periferias das grandes cidades da região (Rocha, 2003, p.7). 
O agravamento nas questões de emprego, renda e habitação, tornaram a cidade pólo de atração, resultando no surgimento de novas favelas em áreas públicas ou terrenos não ocupados. Os manguezais continuam sendo áreas alternativas para instalações de favelas. Além das antigas invasões já consolidadas nas avenidas conhecidas como Av. Isabel e Av. Esperança ao longo dos Rios Cachoeira e Fundão, surgiram outras ao longo do Rio Itaconoeiras, onde se localizam os bairros de Vila Nazaré, Savóia, Vila Lídia, além dos bairros Teotônio Vilela e São Domingos, ao longo da BA 001, e a Rua do Mosquito em frente à rodoviária.

Além do litoral sul, tendo Olivença como referência, a expansão turística voltou-se para o litoral norte da cidade. Esta área é rica em diversos ecossistemas e recursos hídricos, além de abrigar diversos animais e plantas endêmicas. Foram criadas duas APAs (Área de Proteção Ambiental): a da Lagoa Encantada pelo Decreto Estadual n 2.217 de 14/07/93 e a de Costa de Itacaré-Serra Grande pelo Decreto Estadual n 2.186 de 07/06/93. O Bairro de São Domingos, loteamento de classe média, encontra-se no litoral norte da cidade, início da rodovia llhéus-Itacaré e teve, nesses últimos anos, o seu manguezal ocupado por uma população de baixa renda.

O Bairro de São Domingos é uma área que se desenvolveu após a década de 70 do século $X X$, quando os vetores de expansão da cidade começaram a serem orientados em direção ao norte com a construção de uma ponte que liga llhéus ao litoral norte. $O$ bairro é caracterizado como residencial com loteamentos para residências de veraneio e permanentes.

Este bairro foi escolhido como área de estudo por apresentar uma paisagem de mangue ainda significativa, mas em processo de degradação com a ocupação de assentamentos humanos de baixa renda. Apesar da crescente ocupação, a análise da área através de metodologias utilizando dados geoprocessados pode fornecer subsídios para auxiliar futuras legislações e formas de fiscalização para preservar a paisagem verde restante ou mesmo recuperar parte dela.

\section{4) Metodologia}

Adotou-se a metodologia aplicada em estudos que utilizam os sistemas de informação geográfica $(\mathrm{SIG})$, visto que engloba técnicas muito importantes e facilitadoras nos estudos que levam em consideração a dinâmica espacial e temporal. O SIG é um sistema computacional composto de hardware, software, dados e procedimentos, construído para capturar gerenciar, analisar, manipular modelar e exibir dados referenciados geograficamente para solucionar, planejar, gerenciar problemas.

Para a realização deste trabalho, recorreu-se ao método da fotointerpretação associado à cartografia digital, para posterior análises espaciais, no qual se utilizou o sistema de informação geográfica ArcView 3.2 a. que foi a ferramenta utilizada na geração e representação espacial dos dados.

Foram utilizadas para o diagnóstico da dinâmica espacial da ocupação antrópica as fotografias aéreas pancromáticas, formato $23 \times 23 \mathrm{~cm}$ do ano de 1964, escala 1: 25.000, tomadas pela empresa GEOFOTO S/A (foto $n^{\circ} 287$ ) e as fotos 492-368, 492-369, 492-370 e 492-371 do ano de 1999, escala 1: 8.000, tomadas pela empresa ENGEFOTO. Com as fotos aéreas do ano de 1999, a Companhia de Desenvolvimento Urbano do Estado da Bahia - CONDER fez uma ortofotocarta de cada uma delas utilizando o AUTOCAD 2000 e que foram usadas aqui. período das fotos conseguidas através dos órgãos citados só possibilitou a comparação entre anos separados por três décadas, não havendo fotos de anos no interior do intervalo entre 1964 e 1999.

O processo de análise espaço-temporal, por sua vez, seguiu as seguintes etapas:

1) Extração das feições de importância para o estudo - com as ortofotocartas da CONDER (1999) de número 492-368, 492-369, 492-370 e 492-371 na escala 1: 2.000 no AUTOCAD 
foram selecionadas as feições ("lawers") denominadas de ruas, mangue, rio/orla, edificação e curvas de níveis, convertendo-as para o formato shapefile no ArcView 3.2 a.

2) Georreferenciamento das fotos aéreas - para o georreferenciamento da foto de 1964 foi necessário utilizar além das ortofotocartas citadas acima as de n 492- 367 e 492- 366 que, apesar de estarem fora da área de estudo, possuíam informações precisas de como eram o canal que liga os rios Itacanoeiros e Almada (construído pelos jesuítas nos primórdios da fundação da cidade) e ruas no já existente bairro do S.Miguel. As coordenadas foram retiradas, escolhendo-se quatro pontos nítidos em cada extremidade da foto e o seu similar na ortofotocarta do AUTOCAD 2000. Através de uma ferramenta específica "Align Tool" do Arcview 3.2 a., foram introduzidas as coordenadas correspondentes e georreferenciadas as fotos. Para a junção das quatro fotos de 1999, foram escolhidos dois pontos de controle em cada extremidade das fotos e esses dois pontos foram georreferenciados em cada uma delas.

3) Sobreposição das feições escolhidas sobre a foto de 1964 - com a foto de 1964 já georreferenciada, foram sobrepostas as feições das ruas (em vermelho), rios (em azul) e mangue (em verde) correspondentes às fotos de 1999 e se pôde comparar a evolução do crescimento urbano desta área da cidade de llhéus, como se vê no exemplo da figura 1.
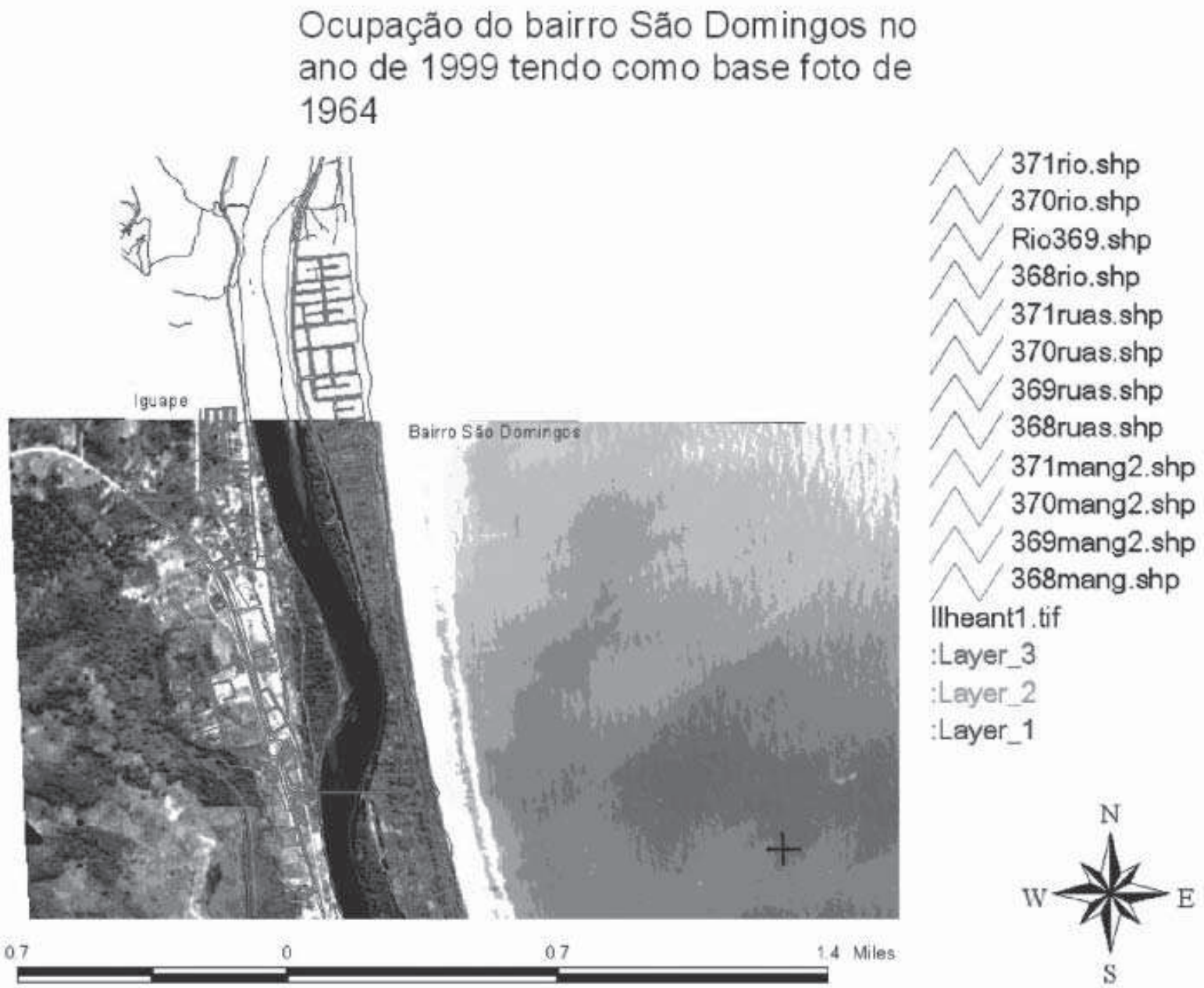

Figura 1: Litoral Norte da cidade de llhéus Fonte: CEPLAC, 1964

4) Criação de temas usando a ferramenta de construção de polígonos - para se calcular a área de ocupação antrópica do manguezal no Bairro São Domingos, foi criado um novo tema 
com a construção de uma poligonal denominada "ocumgshp" ao seu redor (vide figura 2). $\mathrm{Na}$ figura a delimitação desta poligonal é firmada em vermelho, enquanto as linhas em verde e azul delimitam as áreas de mangue e de rios respectivamente. De acordo com esse cálculo a área de ocupação sobre o mangue encontrada, em 1999, foi de 23.953,24 m².
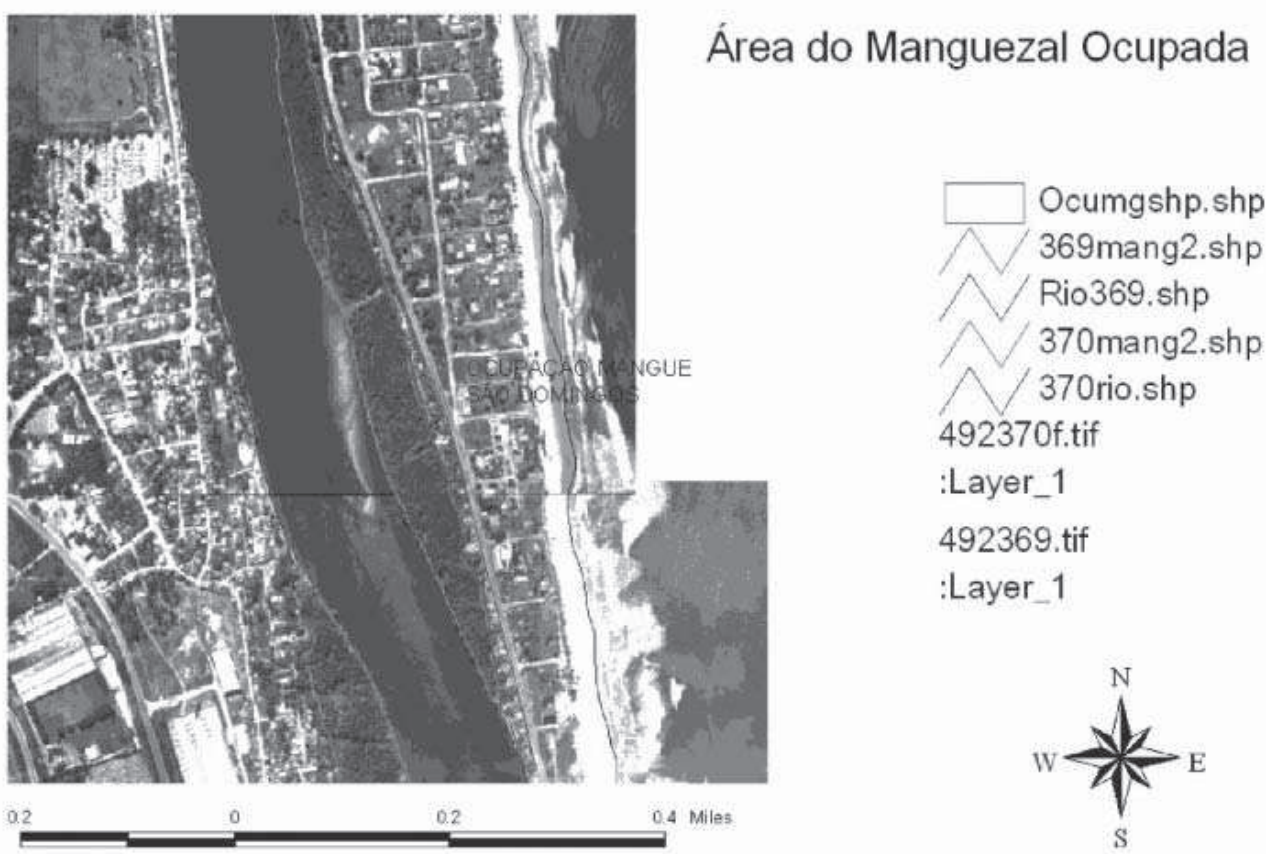

Figura 2: Ocupação do manguezal no bairro São Domingos Fonte: CONDER, 1999

\section{5) Análise dos dados sobre a paisagem}

Analisando as duas figuras que seguem (figura 3 e figura 4) verifica-se que, em 1964, não existia o bairro São Domingos e nem a ponte que dá acesso ao litoral norte da cidade de Ilhéus. Havia algumas habitações no bairro do lguape inclusive algumas residências ocupando o manguezal.

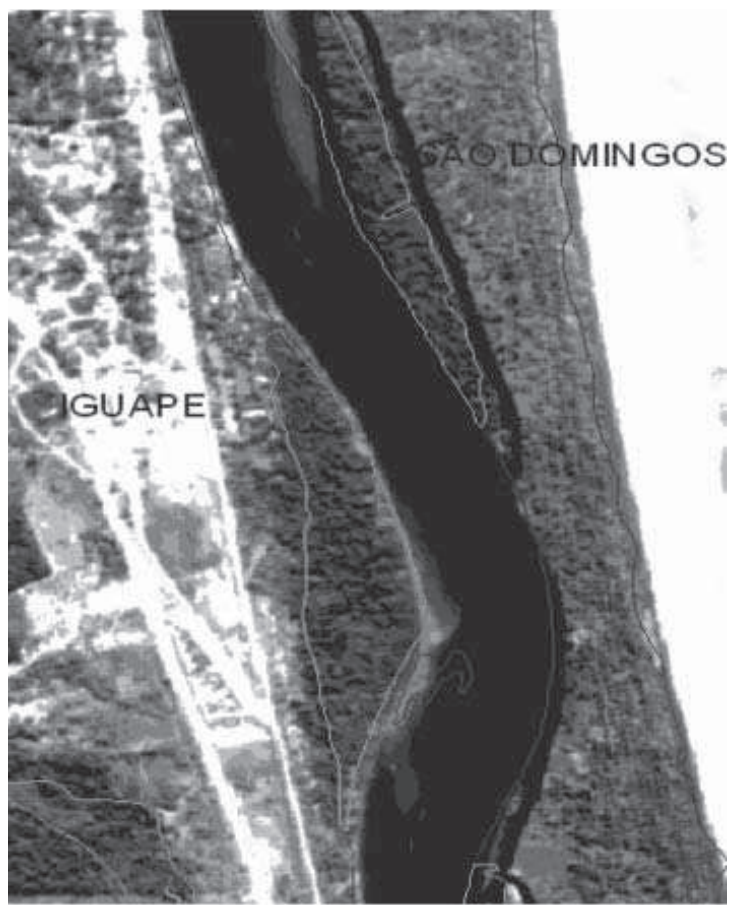

Figura 3: Foto aérea da área de estudo, em 1964 Fonte: CEPLAC, 1964 


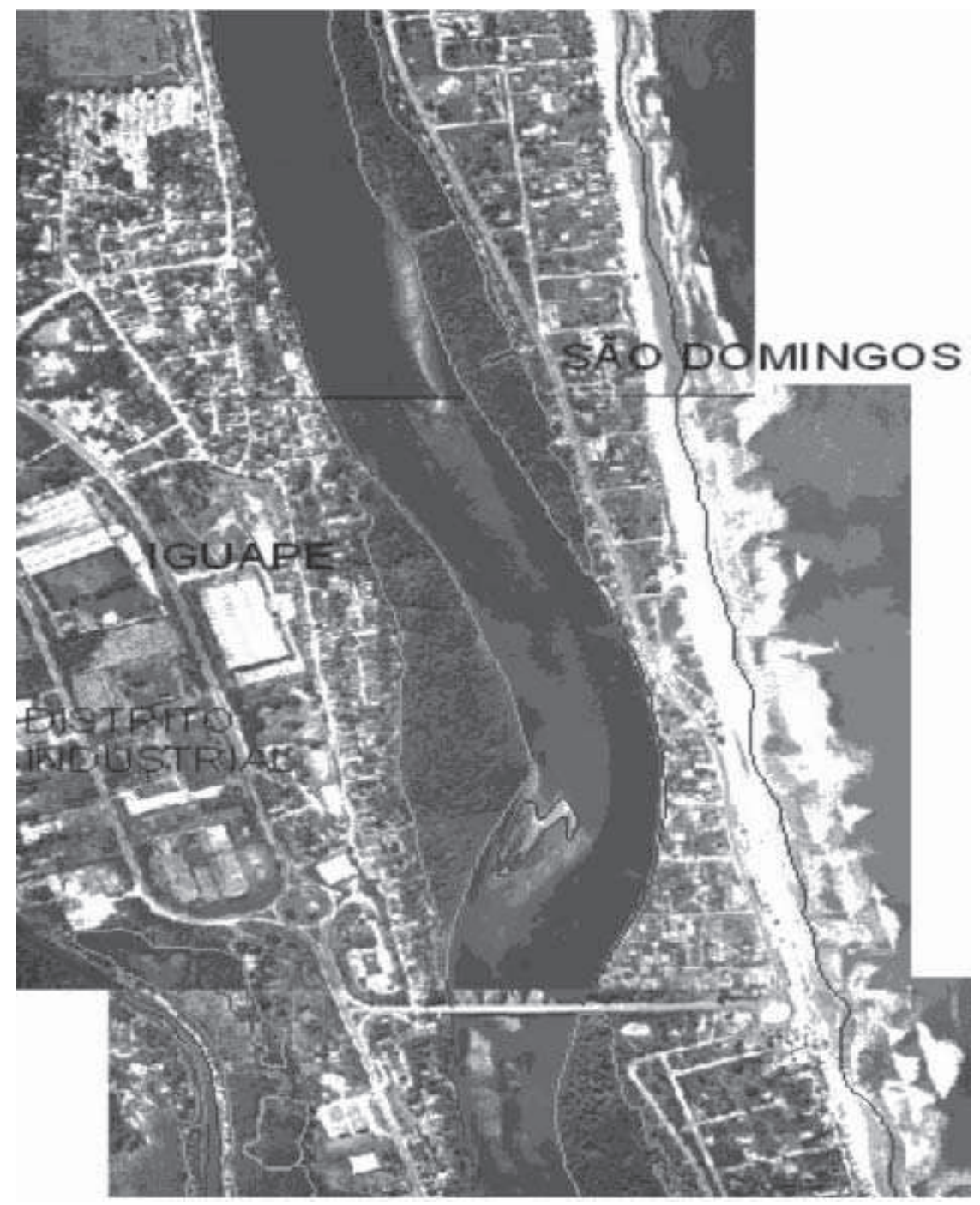

Figura 4: Foto aérea da área de estudo, em 1999

Fonte: CONDER, 1999

Na figura 4 (correspondente à área de estudo), no período de 1999, são observadas grandes alterações: o bairro do lguape torna-se bem mais edificado e nota-se a presença do Distrito Industrial na margem esquerda do Rio Almada. Percebem-se irregularidades como a ocupação antrópica avançando sobre o manguezal, tanto no bairro do lguape quanto no bairro de São Domingos. O bairro de São Domingos encontra-se já implantado, porém não ocupado em sua totalidade, existindo lotes vazios em seu interior. É um bairro de classe média que possui algumas residências de veraneio. $\bigcirc$ sistema viário está definido nestas localidades e podem ser observadas as vias pavimentadas com as duas rótulas de distribuição do tráfego e de acesso à cidade.

Apesar de seis anos de diferença entre a atualidade e o ano de 1999, as mesmas observações foram confirmadas recentemente em visitas locais para averiguação das tipologias de ocupação, principalmente nos limites do mangue.

Na figura 5, do ano de 1999, pode-se notar mais detalhadamente a ocupação do manguezal no bairro São Domingos, através da ampliação de um trecho da foto de 1999. Na esquerda da rodovia, encontra-se a população de baixa renda ocupando o manguezal e na sua direita o loteamento aprovado pelo município com residências de alvenaria num padrão classe média. 


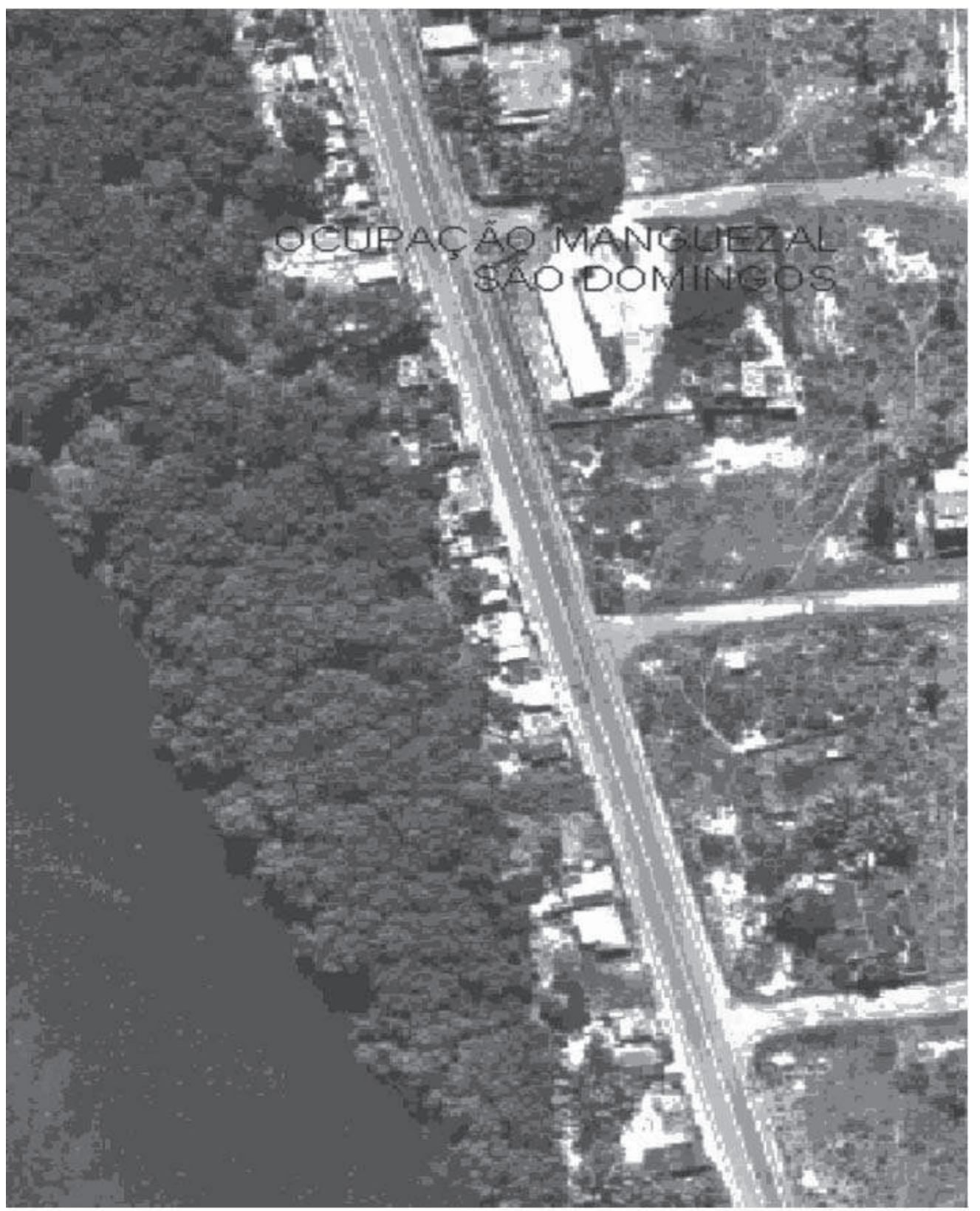

Figura 5: Detalhe da ocupação do manguezal Fonte: CONDER, 1999

Através do sistema computacional, fez-se o cálculo da área de ocupação do manguezal no bairro São Domingos, obtendo-se uma área de 23.953,24 m² como já falado. Espacialmente a área verde no bairro estudado sofreu uma grande redução, havendo um drástico bloqueio do ecossistema entre a faixa que separa o rio da praia. Esta faixa de transição entre o mangue e o mar foi totalmente ocupada por loteamentos e a margem da estrada que limita o mangue e os mesmos loteamentos foi ocupada na sua maior parte pela população de baixa renda (vide figura 5). Em virtude de ser considerada uma APP (Área de Preservação Permanente) pela legislação atual, a área de mangue no Bairro de São Domingos apresenta ocupação irregular com relação à presença de casas e de um processo de favelização na margem esquerda da estrada, invadindo literalmente o interior do mangue.

Por enquanto, com os dados resultantes do SIG e também com as informações colhidas atualmente em entrevistas informais nas visitas exploratórias ao local, sugere-se que houve uma forte negligência dos órgãos fiscalizadores competentes tanto da Prefeitura Municipal de llhéus como 
do CRA - Centro de Recursos Ambientais e do IBAMA (Instituto Brasileiro do Meio Ambiente e dos Recursos Naturais Renováveis). Todos eles em conjunto com a população deveriam estar trabalhando no sentido de definir com precisão os limites da área de preservação ambiental para proteger o mangue.

O SIG utilizado se mostrou eficiente no sentido de determinar a redução dos recursos naturais provocados, a partir da implantação dos bairros no litoral Norte de llhéus, em particular o de São Domingos. Contudo, o estudo ainda necessita ser aprofundado, podendo-se ainda através do SIG contrapor outras variáveis como econômicas e sociais para se determinar os fatores que mais pesaram na degradação do mangue para se propor futuramente programas de preservação ambiental na área, conservando-se e/ou restaurando-se a paisagem de mangue atual.

\section{6) Considerações finais}

A utilização do sistema de informação geográfica (SIG) no estudo da transformação da paisagem decorrente expansão de áreas urbanas, permite avaliar a dinâmica da ocupação antrópica, tanto a nível espacial como temporal, consolidando-se como metodologia importante em pesquisa na área de urbanismo e planejamento ambiental e urbano. O SIG através da construção de planos de informação possibilitou à compreensão de características físicas e humanas do espaço estudado. É importante ressaltar que os arquivos digitais possibilitam a atualização dos planos de informação a qualquer momento.

Pelo resultado obtido da comparação entre as fotos aéreas do período de 1964 e 1999 pode-se perceber como se deu o processo de urbanização na área de estudo e também, as irregularidades destas ocupações em áreas de manguezais, confirmando mais uma vez a validade da técnica de SIG como ferramenta para estudos sobre a paisagem.

\section{Bibliografia}

CONDER. Companhia de Desenvolvimento Urbano do Estado da Bahia. ENGEFOTO, 1999. Fotos n. 492-366, 492367, 492-368, 492-369, 492-370 e 492-371.

CEPLAC. Comissão Executiva do Plano da Lavoura Cacaueira. GEOFOTO, 1964.

LACERDA, Luiz Drude. Os manguezais do Brasil. In: VANNUCCl, Marta. Os manguezais e nós: Uma síntese de percepções. São Paulo: Edusp, 1999.

MACIEL, Norma Crud. Alguns aspectos da ecologia do manguezal. In: CPRH. Alternativas de uso e proteção dos manguezais do Nordeste. Recife: Companhia Pernambucana de Controle da Polvição Ambiental e de Administração dos Recursos Hídricos, n. 3, 1991. Série Publicações Técnicas.

RAMOS, Sérgio. Manguezais da Bahia: Breves considerações. Ilhéus: Editus, 2002.

ROCHA, Dione. Favelas e degradação do meio ambiente. Jornal Agora, Itabuna - BA, ano I, n. 10, mar. 2003, p. 7.

SEPLANTEC/CEI. Secretaria do Planejamento, Ciência e Tecnologia. Centro de Estatística e Informações. Informações básicas dos municípios baianos: Região Litoral Sul. Salvador: Seplantec/CEI, 1996. 
Paisagem Ambiente: ensaios - n. 24 - São Paulo - p. 39 - 48 - 2007 